\title{
BMJ Open Association between low-density lipoprotein cholesterol level and mortality in patients with cardiogenic shock: a retrospective cohort study
}

Jiali Jin, ${ }^{1}$ Zhewei Shi, ${ }^{1}$ Xiaomin Pang (1) ${ }^{2}$

To cite: Jin J, Shi Z, Pang X. Association between lowdensity lipoprotein cholesterol level and mortality in patients with cardiogenic shock: a retrospective cohort study. BMJ Open 2021;11:e044668. doi:10.1136/ bmjopen-2020-044668

- Prepublication history for this paper is available online. To view these files, please visit the journal online (http://dx.doi. org/10.1136/bmjopen-2020044668).

Received 16 0ctober 2020 Accepted 20 May 2021
Check for updates

(c) Author(s) (or their employer(s)) 2021. Re-use permitted under CC BY-NC. No commercial re-use. See rights and permissions. Published by BMJ.

${ }^{1}$ Department of Cardiology, Zhuji People's Hospital of Zhejiang Province, Zhuji, China ${ }^{2}$ Department of Emergency, People's Hospital of Tiantai County, Taizhou, Zhejiang, China

Correspondence to

Dr Xiaomin Pang;

congcong1035@163.com

\section{ABSTRACT}

Aims Inflammation plays a key role in the pathophysiology of cardiogenic shock (CS). Lowdensity lipoprotein cholesterol (LDL-C) is a biomarker of inflammation and is used to predict prognostic outcomes of several diseases. The primary purpose of this study was to evaluate if LDL-C can be used as a biomarker to predict the mortality of CS.

Methods and results Records of critically ill patients with CS were identified from the Medical Information Mart for Intensive Care III database. A multivariate Cox regression model was employed to adjust for imbalances by incorporating parameters and potential confounders. A total of 551 critically ill patients with CS were enrolled for this analysis, including 207 with LDL-C $<1.8 \mathrm{mmol} / \mathrm{L}$ and 344 with $L D L-C \geq 1.8 \mathrm{mmol} / \mathrm{L}$. Results of multivariate Cox regression models found that higher concentration of LDL-C (LDL-C $\geq 1.8 \mathrm{mmol} / \mathrm{L}$ ) was associated with a reduced risk of in-hospital mortality ( $\mathrm{HR} 0.66,95 \% \mathrm{Cl} 0.50$ to $0.87 ; p=0.003$ ) and 28-day mortality (HR $0.61,95 \% \mathrm{Cl}$ 0.46 to $0.80 ; p=0.002) \mathrm{LDL}-\mathrm{C}$ in patients with CS. Patients with $\mathrm{LDL}-\mathrm{C} \geq 1.8 \mathrm{mmol} / \mathrm{L}$ were independently associated with improved in-hospital survival (HR $0.32,95 \% \mathrm{Cl} 0.20$ to $0.52, \mathrm{p}<0.001)$ and 28 -day survival $(\mathrm{HR} 0.51,95 \% \mathrm{Cl}$ 0.33 to $0.73, p=0.002$ ) compared with patients with $\mathrm{LDL}-\mathrm{C}<1.8 \mathrm{mmol} / \mathrm{L}$. The impact of LDL-C on in-hospital mortality and 28-day mortality persisted in patients with acute coronary syndrome (ACS) and was not statistically significant in the non-ACS subgroup.

Conclusions Our study observed that increased LDL-C level was related with improved survival in patients with $\mathrm{CS}$, but not with improved outcomes in patients with uncomplicated ACS. The results need to be verified in randomised controlled trials.

\section{INTRODUCTION}

Cardiogenic shock (CS) continues to be associated with poor prognosis and acute coronary syndrome (ACS) remains the most common cause of CS. ${ }^{1-3}$ Despite advances in pharmacological and mechanical circulatory support (MCS), short-term mortality remains as high as $35 \%-40 \%$ in recent studies. ${ }^{4-7}$ Inflammatory markers and cytokines have demonstrated predictive power for mortality
Strengths and limitations of this study

- This was the first study to explore the prognostic value of low-density lipoprotein cholesterol (LDL-C) level in patients with cardiogenic shock.

- A multivariate Cox proportional hazards model and Kaplan-Meier model were used in the study.

- This was a retrospective observational study in a single centre.

- The sample size of patients selected was small.

- The level of LDL-C was measured only when patients were first admitted to the intensive care unit.

of patients with $\mathrm{CS},{ }^{89}$ however, these inflammatory factors are not commonly measured in clinical practice.

Low-density lipoprotein cholesterol (LDL-C) is an important risk factor for $\mathrm{ACS}^{1011}$ and plays a key role in the inflammatory procedure. ${ }^{12}$ Recent studies have found that initial LDL-C level was inversely associated with mortality in patients with ACS. ${ }^{13-16}$ Meanwhile, data from large observational studies revealed that LDL-C may function as an inflammatory biomarker and is predictive of poor outcome in those with rheumatoid arthritis, heart failure, stroke and atrial fibrillation. ${ }^{17-23}$

Thus, we hypothesised that LDL-C may affect the prognosis of CS. However, the association between LDL-C and mortality in patients with CS remains unknown, and this study aimed to clarify the association.

\section{METHODS}

\section{Data source}

We extracted data from the Medical Information Mart for Intensive Care III V.1.4 (MIMIC-III, V.1.4), a publicly available and freely accessible intensive care unit (ICU) database. ${ }^{24}$ The MIMIC-III database contains comprehensive, time-stamped information 
for more than 60000 ICU patients (medical, surgical, coronary care and neonatal) admitted to Beth Israel Deaconess Medical Centre (Boston, Massachusetts, USA) from 1 June 2001 to 31 October 2012 (single centre), representing more than 46000 patients.

\section{Study subjects}

Patients in our study were selected from persons in MIMIC-III aged $\geq 18$ years at ICU admission with CS (ICD-9-CM (International Classification of Diseases-9Clinical Modification) diagnosis codes 785.51 or 998.01), plus any of the following criteria: minimum systolic blood pressure $<90 \mathrm{~mm} \mathrm{Hg}$, or need for vasopressors therapy (any of dopamine, epinephrine, norepinephrine, phenylephrine, vasopressin), or with signs of hypoperfusion (first 24 hours of urine output $<400 \mathrm{~mL}$ or maximum blood lactate $>2 \mathrm{mmol} / \mathrm{L})$. Patients with LDL-C measurement at the initial 48 hours of ICU entry were included. Of these patients, we excluded patients with $\leq 0$ days or $\geq 100$ days between ICU admission and discharge, defined as the earliest documented ICU discharge, hospital discharge or time of death. If patients who had multiple admissions to ICU, only the first ICU admission was included for analysis. Patients were also excluded as follows: 1 . With more than $10 \%$ individual data missing; 2. Individual data values exceeded the mean \pm 3 times the $\mathrm{SD}$

\section{Data extraction}

The following variables were extracted from the MIMIC-III database for the first day of ICU admission: age at the time of hospital admission, gender, ACS, LDL-C level, Acute Physiology Score III (APS III), Simplified Acute Physiology Score II, use of MCS, maximum lactate, maximum creatinine, maximum bilirubin, maximum international normalised ratio (INR), mean heart rate, mean of mean blood pressure, urine output first day after ICU entry, using milrinone, dobutamine, dopamine, epinephrine, norepinephrine, phenylephrine, vasopressin, mechanical ventilation and renal replacement therapy (RRT). If a variable was measured more than once in the first 24 hours, the maximum value was used.

The primary end point was the in-hospital mortality and 28-day mortality, which were defined as the survival status of patients at discharge and at day 28.

\section{Statistical analysis}

According to the target level of LDL-C in current guidelines, ${ }^{10} 11$ the study population was categorised into low LDL-C (LDL-C $<1.8 \mathrm{mmol} / \mathrm{L}$ ) and high LDL-C (LDL-C $\geq 1.8 \mathrm{mmol} / \mathrm{L}$ ) groups. Categorical variables were expressed as the number of percentages. They were compared between the low LDL-C and high LDL-C groups with $\chi^{2}$ test or Fisher's exact test, as appropriate. Continuous variables were expressed as mean (SD) or median (IQR) with variance analysis or the Wilcoxon test, as appropriate.

We selected these potential confounders on the basis of their associations with the outcomes of interest or a

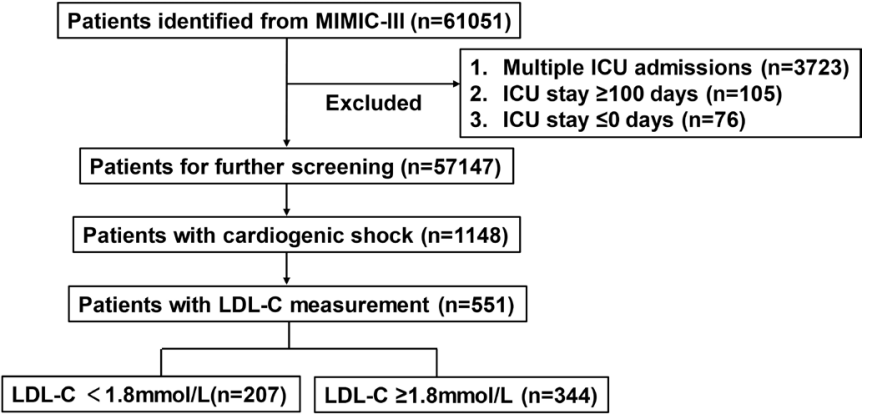

Figure 1 Flow chart of patient selection. ICU, intensive care unit; LDL-C, low-density lipoprotein cholesterol; MIMIC-III, Medical Information Mart forlntensive Care III,

change in effect estimate of $>10 \%$ or values of $p<0.1$ in univariable analyses, as well as on strong clinical judgement. The multivariate Cox proportional hazards model and Kaplan-Meier model were used for survival analysis to adjust for imbalance by including parameters and potential confounders judged by clinical expertise.

A two-tailed value of $p<0.05$ was considered to be statistically significant. EmpowerStats V.2.17.8 (http://www. empowerstats.com/) and R software V.3.42 were used for all statistical analysis.

\section{RESULTS}

\section{Subject characteristics}

A total of 551 critically ill patients with CS were eligible for this analysis (figure 1). Table 1 shows the baseline characteristics of the low LDL-C (LDL-C $<1.8 \mathrm{mmol} / \mathrm{L}$ ) and high LDL-C (LDL-C $\geq 1.8 \mathrm{mmol} / \mathrm{L}$ ) groups. There were higher baseline measures in the low LDL-C group, including age, maximum lactate, maximum creatinine and maximum INR. Patients in the low LDL-C group were more complicated with ACS, with more use of MCS, milrinone, dopamine and vasopressin. In the low LDL-C group, patients were less likely to be female, had lower APS III scores, mean blood pressure, mean heart rate, maximum bilirubin, and less use of dopamine, while having higher in-hospital and 28-day mortality.

\section{Association between LDL-C level and mortality}

The Kaplan-Meier survival estimate is shown in figure 2. During the in-hospital and 28-day follow-up periods, patients with LDL-C $\geq 1.8 \mathrm{mmol} / \mathrm{L}$ were associated with improved survival $(\mathrm{p}<0.001)$, as compared with patients with $\mathrm{LDL}-\mathrm{C}<1.8 \mathrm{mmol} / \mathrm{L}$.

Multivariate Cox regression model results demonstrated that higher level of LDL-C was associated with decreased risk of in-hospital mortality (HR 0.66, 95\% CI 0.50 to $0.87 ; \mathrm{p}=0.003$ ) and 28-day mortality (HR 0.61 , $95 \%$ CI 0.46 to $0.80 ; p=0.002$ ) in patients with $\mathrm{CS}$, after adjusting for age, gender, APS III, ASPS II, use of MCS, mechanical ventilation, RRT, milrinone, dobutamine, dopamine, epinephrine, norepinephrine, phenylephrine and vasopressin. 
Table 1 Baseline Characteristics*

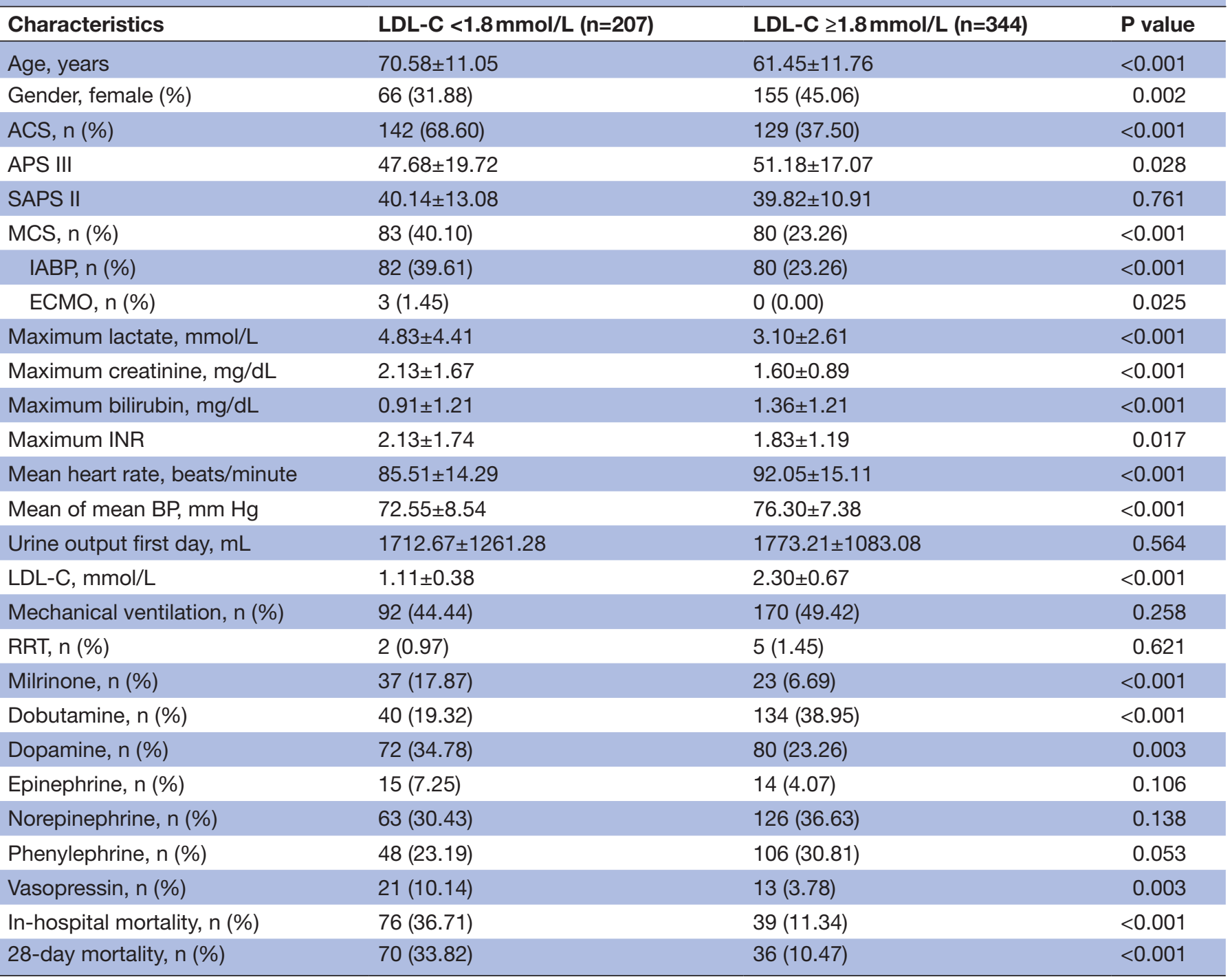

*plus-minus values are means \pm SD.

ACS, acute coronary syndrome; APS III, Acute Physiology Score III; BP, blood pressure; ECMO, extracorporeal membrane oxygenation; IABP, intra-aortic balloon pump; INR, international normalised ratio; LDL-C, Low-density lipoprotein cholesterol; MCS, mechanical circulatory support; RRT, renal replacement therapy; SAPS II, Simplified Acute Physiology Score II.
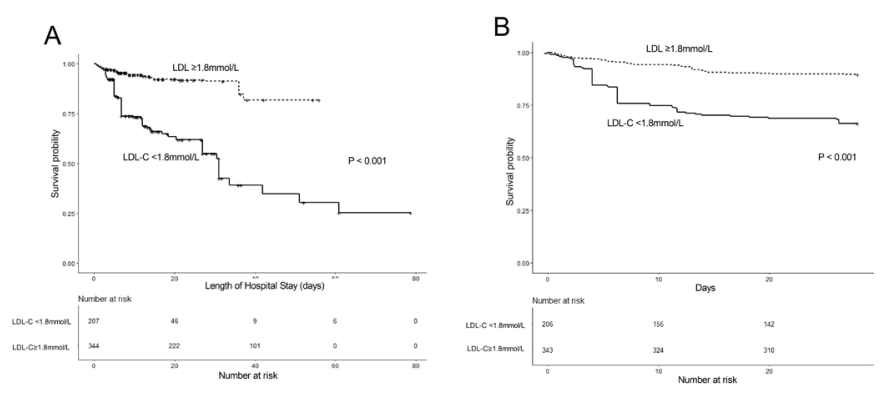

Figure 2 Kaplan-Meier survival from in-hospital mortality and 28-day mortality for patients with LDL-C $<1.8 \mathrm{mmol} / \mathrm{L}$ and LDL-C $\geq 1.8 \mathrm{mmol} / \mathrm{L}$. LDL-C, low-density lipoprotein cholesterol.
Compared with patients in the reference group (LDL-C $<1.8 \mathrm{mmol} / \mathrm{L})$, patients with CS with LDL-C $\geq 1.8 \mathrm{mmol} / \mathrm{L}$ were still independently related with improved in-hospital survival (HR $0.32,95 \%$ CI 0.20 to $0.52, \mathrm{p}<0.001$ ) and 28-day survival (HR $0.51,95 \%$ CI 0.33 to $0.73, \mathrm{p}=0.002$ ), adjusting for these potential confounders (table 2 ).

\section{Subgroup analysis for patients with or without ACS in CS}

There were $49.73 \%$ patients in CS complicated with ACS. Subgroup analysis was conducted among patients with ACS and non-ACS, as shown in figure 3. The relationship of LDL-C with in-hospital mortality (HR $0.36,95 \%$ CI 0.21 to $0.60, \mathrm{p}<0.001$ ) as well as 28-day mortality (HR 0.53 , $95 \%$ CI 0.34 to $0.83, \mathrm{p}=0.002)$, remained in patients with ACS but was not statistically significant in the non-ACS subgroup. 
Table 2 Association of LDL-C and in-hospital mortality and 28-day mortality by Cox regression after the multivariable model

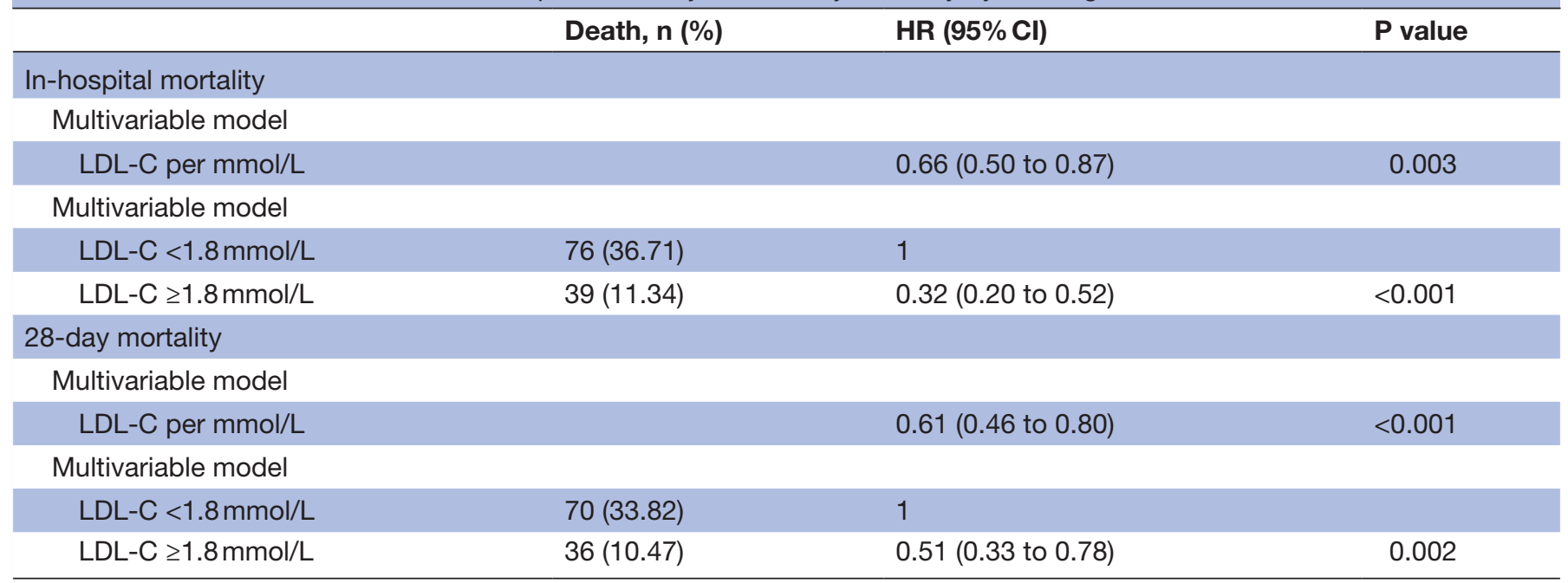

LDL-C, low-density lipoprotein cholesterol.

\section{DISCUSSION}

In the present retrospective study, data on survival end points showed that initially a higher level of LDL-C conferred a significantly lower risk of in-hospital mortality with an HR of 0.66 and 28-day mortality HR of 0.61 . This inverse relationship was only statistically significant in patients of the ACS subgroup.

Previous randomised clinical studies, in addition to biological and experimental evidence, have provided convincing evidence that LDL-C is causally associated with the risk of coronary artery disease..$^{11}{ }^{11}$ However, a number of studies have reported a protective association between higher concentrations of LDL-C and ACS. ${ }^{13-15}$ In the Global Registry of Acute Coronary Events mortality model, lower in-hospital mortality was associated with hypercholesterolaemia in patients with ACS. ${ }^{16}$ Meanwhile, an increased level of LDL-C was also associated with a lower risk of 30-day mortality, 1 year mortality and even 5-year mortality in patients with ACS, ${ }^{13-16}$ respectively. To our knowledge, this 'lipid paradox' has not been reported in critically ill patients with CS. Indeed, we explored this paradox in the current study of patients

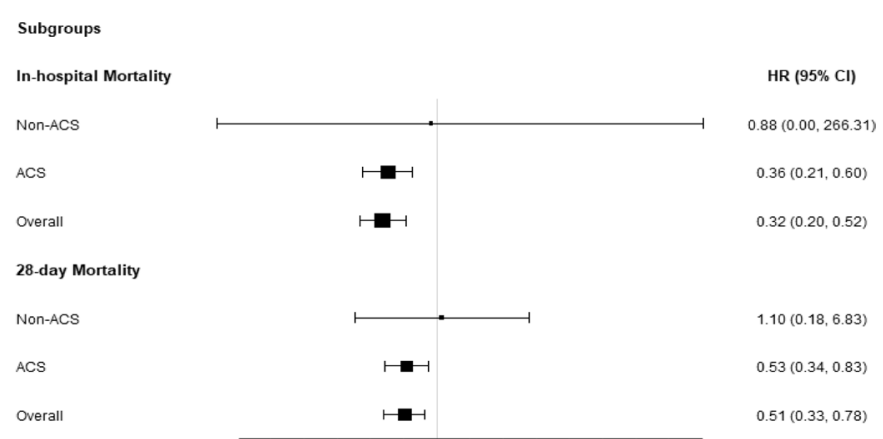

Figure 3 Subgroup analyses of in-hospital mortality and 28-day mortality among patients with ACS and non-ACS for patients in the LDL-C $<1.8 \mathrm{mmol} / \mathrm{L}$ and $\mathrm{LDL}-\mathrm{C} \geq 1.8 \mathrm{mmol} / \mathrm{L}$ groups. ACS, acutecoronary syndrome. with CS and found a significant protective effect of LDL-C on hospitalisation and 28-day mortality after adjustment.

In our study, subgroup analysis showed that this lipid paradox was only statistically significant in patients with ACS. This should be mainly due to the inflammatory procedure for the underlying pathophysiology of patients with CS complicated with ACS. ${ }^{89}$ Data from observational studies reported lower lipid levels in patients with active rheumatoid arthritis and postulated that this may be due to inflammatory processes. ${ }^{23}$ An inflammatory biomarker release is also observed in acute pancreatitis in which the lipid paradox has been observed. ${ }^{25}$ This inflammatory hypothesis has recently been reinforced in the Canakinumab Anti-inflammatory Thrombosis Outcome Study Trial, which studied the use of the orphan drug canakinumab to reduce the risk of developing cardiovascular events, using anti-inflammatory therapy with interleukin- $1 \beta$ inhibition. ${ }^{26}$

There are several limitations worth mentioning. Above all, there is a lack of randomisation and data from a single US centre were used, which may lead to selection bias. Second, in-hospital mortality and 28-day mortality were used, which may affect the assessment of long-term prognosis. In addition, it is to be noted that the nature of our study was observational, and this paradox relationship between lower LDL-C levels and mortality should be further tested in a randomised controlled study.

\section{CONCLUSIONS}

In conclusion, in this study cohort of patients with CS, patients with high LDL-C levels were associated with lower in-hospital mortality and 28-day mortality compared with patients with low LDL-C levels. However, this relationship was only statistically significant in patients complicated with ACS. These findings should be prospectively evaluated by randomised controlled trials. 
Contributors $\mathrm{JJ}$ and $\mathrm{ZS}$ conducted all the experiments. $\mathrm{JJ}$ and XP wrote and revised the manuscript; ZS conducted most of the analysis of data.

Funding This work was supported by grants from the Science and Technology Project of Zhejiang Provincial Health Commission (2019RC299).

Competing interests None declared.

Patient and public involvement Patients and/or the public were not involved in the design, or conduct, or reporting, or dissemination plans of this research.

Patient consent for publication Not required.

Ethics approval Since the database was approved by the Institutional Review Boards (IRB) of Beth Israel Deaconess Medical Center (Boston, Massachusetts, USA) and the Massachusetts Institute of Technology (Cambridge, Massachusetts, USA), IRB approval from the authors' institution was exempted.

Provenance and peer review Not commissioned; externally peer reviewed.

Data availability statement The data sets used and/or analysed during the current study are available from the corresponding author on reasonable request.

Open access This is an open access article distributed in accordance with the Creative Commons Attribution Non Commercial (CC BY-NC 4.0) license, which permits others to distribute, remix, adapt, build upon this work non-commercially, and license their derivative works on different terms, provided the original work is properly cited, appropriate credit is given, any changes made indicated, and the use is non-commercial. See: http://creativecommons.org/licenses/by-nc/4.0/.

ORCID iD

Xiaomin Pang http://orcid.org/0000-0002-8918-4277

\section{REFERENCES}

1 Thiele H, Ohman EM, Desch S, et al. Management of cardiogenic shock. Eur Heart J 2015;36:1223-30.

2 Mebazaa A, Tolppanen $\mathrm{H}$, Mueller $\mathrm{C}$, et al. Acute heart failure and cardiogenic shock: a multidisciplinary practical guidance. Intensive Care Med 2016;42:147-63.

3 van Diepen S, Katz JN, Albert NM, et al. Contemporary management of cardiogenic shock: a scientific statement from the American heart association. Circulation 2017;136:e232-68.

4 Hunziker L, Radovanovic D, Jeger R, et al. Twenty-Year trends in the incidence and outcome of cardiogenic shock in AmiS plus registry. Circ Cardiovasc Interv 2019;12:e007293.

5 Berg DD, Bohula EA, van Diepen S, et al. Epidemiology of shock in contemporary cardiac intensive care units. Circ Cardiovasc Qual Outcomes 2019;12:e005618.

6 Thiele H, Jobs A, Ouweneel DM, et al. Percutaneous shortterm active mechanical support devices in cardiogenic shock: a systematic review and collaborative meta-analysis of randomized trials. Eur Heart J 2017;38:3523-31.

7 Thiele H, Zeymer U, Neumann F-J, et al. Intraaortic balloon support for myocardial infarction with cardiogenic shock. N Engl J Med 2012;367:1287-96.

8 Prondzinsky R, Unverzagt S, Lemm H, et al. Interleukin-6, -7, -8 and -10 predict outcome in acute myocardial infarction complicated by cardiogenic shock. Clin Res Cardiol 2012;101:375-84.

9 Prondzinsky R, Unverzagt S, Lemm H, et al. Acute myocardial infarction and cardiogenic shock: prognostic impact of cytokines:
INF- $\gamma$, TNF- $\alpha$, MIP-1 $\beta$, G-CSF, and MCP-1 $\beta$. Med Klin Intensivmed Notfmed 2012;107:476-84.

10 Authors/Task Force Members, ESC Committee for Practice Guidelines (CPG), ESC National Cardiac Societies. 2019 ESC/ EAS guidelines for the management of dyslipidaemias: lipid modification to reduce cardiovascular risk. Atherosclerosis 2019;290:140-205.

11 Grundy SM, Stone NJ, Bailey AL, et al. 2018 AHA/ACC/AACVPR/ AAPA/ABC/ACPM/ADA/AGS/APhA/ASPC/NLA/PCNA Guideline on the Management of Blood Cholesterol: A Report of the American College of Cardiology/American Heart Association Task Force on Clinical Practice Guidelines. J Am Coll Cardiol 2019;73:e285-350.

12 Chistiakov DA, Bobryshev YV, Orekhov AN. Macrophagemediated cholesterol handling in atherosclerosis. J Cell Mol Med 2016;20:17-28.

13 Cheng K-H, Chu C-S, Lin T-H, et al. Lipid paradox in acute myocardial infarction-the association with 30-day in-hospital mortality. Crit Care Med 2015;43:1255-64.

14 Wang TY, Newby LK, Chen AY, et al. Hypercholesterolemia paradox in relation to mortality in acute coronary syndrome. Clin Cardiol 2009;32:E22-8.

15 Sia $\mathrm{C}-\mathrm{H}$, Zheng H, Ho AF-W, et al. The lipid paradox is present in STelevation but not in non-ST-elevation myocardial infarction patients: insights from the Singapore myocardial infarction registry. Sci Rep 2020;10:6799.

16 Granger CB, Goldberg RJ, Dabbous O, et al. Predictors of hospital mortality in the global registry of acute coronary events. Arch Intern Med 2003;163:2345-53.

17 Güder G, Frantz S, Bauersachs J, et al. Reverse epidemiology in systolic and nonsystolic heart failure: cumulative prognostic benefit of classical cardiovascular risk factors. Circ Heart Fail 2009;2:563-71

18 Rauchhaus M, Clark AL, Doehner W, et al. The relationship between cholesterol and survival in patients with chronic heart failure. J Am Coll Cardiol 2003;42:1933-40.

19 Schatz IJ, Masaki K, Yano K, et al. Cholesterol and all-cause mortality in elderly people from the Honolulu heart program: a cohort study. Lancet 2001;358:351-5.

20 Markaki I, Nilsson U, Kostulas K, et al. High cholesterol levels are associated with improved long-term survival after acute ischemic stroke. J Stroke Cerebrovasc Dis 2014;23:e47-53.

21 Lopez FL, Agarwal SK, Maclehose RF, et al. Blood lipid levels, lipid-lowering medications, and the incidence of atrial fibrillation: the Atherosclerosis risk in Communities study. Circ Arrhythm Electrophysiol 2012;5:155-62.

22 Myasoedova E, Crowson CS, Kremers HM, et al. Lipid paradox in rheumatoid arthritis: the impact of serum lipid measures and systemic inflammation on the risk of cardiovascular disease. Ann Rheum Dis 2011;70:482-7.

23 Amezaga Urruela M, Suarez-Almazor ME. Lipid paradox in rheumatoid arthritis: changes with rheumatoid arthritis therapies. Curr Rheumatol Rep 2012;14:428-37.

24 Johnson AEW, Pollard TJ, Shen L, et al. MIMIC-III, a freely accessible critical care database. Sci Data 2016;3:160035.

25 Hong W, Zimmer V, Stock S, et al. Relationship between low-density lipoprotein cholesterol and severe acute pancreatitis ("the lipid paradox"). Ther Clin Risk Manag 2018;14:981-9.

26 Ridker PM, Everett BM, Thuren T, et al. Antiinflammatory therapy with canakinumab for atherosclerotic disease. $N$ Engl J Med 2017;377:1119-31. 